\title{
Pulmonary function impairment in patients with combined pulmonary fibrosis and emphysema with and without airflow obstruction
}

This article was published in the following Dove Press journal:

International Journal of COPD

29 July 2014

Number of times this article has been viewed

\section{Yoshiaki Kitaguchi ${ }^{1,2}$ \\ Keisaku Fujimoto ${ }^{3}$ \\ Masayuki Hanaoka' \\ Takayuki Honda ${ }^{4}$ \\ Junichi Hotta ${ }^{2}$ \\ Jiro Hirayama ${ }^{2}$}

'First Department of Internal Medicine, Shinshu University School of Medicine, Matsumoto, ${ }^{2}$ Department of Internal Medicine, Okaya City Hospital, Okaya,

${ }^{3}$ Department of Clinical Laboratory Sciences, ${ }^{4}$ Department of Laboratory Medicine, Shinshu University School of Medicine, Matsumoto, Japan
Correspondence: Keisaku Fujimoto Department of Clinical Laboratory Sciences, Shinshu University School of Health Sciences, 3-I-I Asahi, Matsumoto, Nagano 390-8621, Japan Tel +8I 263372393

Fax +8I 263372370

Email keisaku@shinshu-u.ac.jp
Background: The syndrome of combined pulmonary fibrosis and emphysema (CPFE) is a recently described entity associating upper-lobe emphysema and lower-lobe fibrosis. We sought to evaluate differences in pulmonary function between CPFE patients with and without airflow obstruction.

Subjects and methods: Thirty-one CPFE patients were divided into two groups according to the presence or absence of irreversible airflow obstruction based on spirometry (forced expiratory volume in 1 second/forced vital capacity $<70 \%$ following inhalation of a $\beta_{2}$-agonist) as follows: CPFE patients with airflow obstruction $\left(\mathrm{CPFE} \mathrm{OB}^{+}\right.$group, $\left.\mathrm{n}=11\right)$, and CPFE patients without airflow obstruction ( $\mathrm{CPFE} \mathrm{OB}^{-}$group, $\mathrm{n}=20$ ). Pulmonary function, including respiratory impedance evaluated using impulse oscillometry and dynamic hyperinflation following metronomepaced incremental hyperventilation, was retrospectively analyzed in comparison with that observed in 49 chronic obstructive pulmonary disease (COPD) patients $(n=49)$.

Results: In imaging findings, low-attenuation-area scores on chest high-resolution computed tomography, representing the degree of emphysema, were significantly lower in the $\mathrm{CPFE} \mathrm{OB}^{-}$ group than in the $\mathrm{CPFE} \mathrm{OB}^{+}$and $\mathrm{COPD}$ groups. In contrast, the severity of pulmonary fibrosis

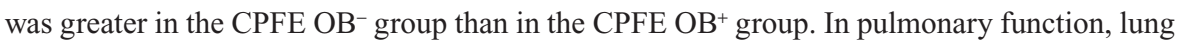
hyperinflation was not apparent in the $\mathrm{CPFE} \mathrm{OB}^{-}$group. Impairment of diffusion capacity was severe in both the $\mathrm{CPFE} \mathrm{OB}^{-}$and $\mathrm{CPFE} \mathrm{OB}^{+}$groups. Impulse oscillometry showed that respiratory resistance was not apparent in the $\mathrm{CPFE} \mathrm{OB}^{-}$group compared with the COPD group, and that easy collapsibility of small airways during expiration of tidal breath was not apparent in the CPFE $\mathrm{OB}^{+}$group compared with the COPD group. Dynamic hyperinflation following metronome-paced incremental hyperventilation was significantly greater in the COPD group than in the $\mathrm{CPFE} \mathrm{OB}^{-}$group, and also tended to be greater in the $\mathrm{CPFE} \mathrm{OB}^{+}$group than in the $\mathrm{CPFE} \mathrm{OB}^{-}$group.

Conclusion: The mechanisms underlying impairment of physiological function may differ among $\mathrm{CPFE} \mathrm{OB}{ }^{+}$patients, $\mathrm{CPFE} \mathrm{OB}^{-}$patients, and $\mathrm{COPD}$ patients. $\mathrm{CPFE}$ is a heterogeneous disease, and may have distinct phenotypes physiologically and radiologically.

Keywords: CPFE, COPD, respiratory impedance, dynamic hyperinflation

\section{Introduction}

The syndrome of combined pulmonary fibrosis and emphysema (CPFE) is a recently described entity associating upper-lobe emphysema and lower-lobe fibrosis. ${ }^{1-5}$ In pulmonary function, CPFE is characterized by relatively normal spirometric values with mild airflow obstruction and mild lung hyperinflation, severe impairment of gas exchange, and desaturation during exercise. ${ }^{1-5}$ The relatively normal spirometric values observed in patients with CPFE are usually attributed to the counterbalancing 
effects of the restrictive defect of pulmonary fibrosis and propensity for hyperinflation seen in emphysema. Moreover, preserved airflow may also be explained by increased traction caused by pulmonary fibrosis, preventing the typical expiratory airway collapse seen in emphysema and contributing to stiffening/support of the small airways by peribronchial fibrosis, resulting in the preservation of forced expiratory volume in 1 second $\left(\mathrm{FEV}_{1}\right) .{ }^{6}$ However, some patients with CPFE who show airflow obstruction defined as $\mathrm{FEV}_{1} /$ forced vital capacity $(\mathrm{FVC})<70 \%$ following inhalation of $\beta_{2}$-agonists are sometimes seen in clinical practice. It is unclear whether CPFE patients with airflow obstruction $\left(\mathrm{CPFE} \mathrm{OB}^{+}\right.$) have different clinical characteristics from CPFE patients without airflow obstruction $\left(\mathrm{CPFE} \mathrm{OB}^{-}\right)$or not.

The pathology and imaging findings observed in patients with CPFE are heterogeneous. ${ }^{2}$ The relative contributions of the pathological changes of emphysema and fibrosis can vary among patients with $\mathrm{CPFE}$. In imaging findings, $\mathrm{CPFE}$ occurs as the development of fibrosis superimposed on a known history of emphysema that may modify the disease progression in most cases. ${ }^{7}$ However, it is unclear whether emphysematous and fibrotic lesions progress independently or if one is the result of the development of the other. Therefore, physiological, pathological, and radiological heterogeneity may be characteristic of CPFE.

We hypothesized that mechanisms underlying lung-function impairment may differ between CPFE patients with and without airflow obstruction. In order to clarify this hypothesis, pulmonary function, including respiratory impedance evaluated using impulse oscillometry (IOS) and dynamic hyperinflation following metronome-paced incremental hyperventilation (MPIH), was retrospectively analyzed in $\mathrm{CPFE} \mathrm{OB}^{+}$and $\mathrm{CPFE} \mathrm{OB}^{-}$patients in comparison with that observed in chronic obstructive pulmonary disease (COPD) patients.

\section{Subjects and methods Subjects}

This study details the retrospective analysis of 31 stable CPFE patients with concurrent emphysema and idiopathic diffuse parenchymal lung disease with fibrosis on chest high-resolution computed tomography (HRCT) ${ }^{8,9}$ who met our imaging criteria. These patients were seen at the outpatient clinic of Shinshu University Hospital between October 2009 and October 2012. The CPFE patients were divided into two groups according to the presence or absence of irreversible airflow obstruction based on spirometry $\left(\mathrm{FEV}_{1} / \mathrm{FVC}<70 \%\right.$ following inhalation of $\beta_{2}$-agonists) as follows: $\mathrm{CPFE} \mathrm{OB}^{+}$ group, $\mathrm{n}=11$; $\mathrm{CPFE} \mathrm{OB}^{-}$group, $\mathrm{n}=20$.

The CPFE patients were compared with 49 stable COPD patients who met our imaging criteria. These patients were seen at the outpatient clinic of Shinshu University Hospital between October 2009 and October 2012 (COPD group). The diagnosis of COPD was based on the clinical history and symptoms, including dyspnea during exercise and pulmonary function characterized by irreversible airflow obstruction ( $\mathrm{FEV}_{1} / \mathrm{FVC}<70 \%$ following inhalation of a $\beta_{2}$-agonist), in accordance with GOLD (Global initiative for chronic Obstructive Lung Disease) guidelines. ${ }^{10}$

Stable patients were defined as those who had not suffered from respiratory tract infections or exacerbation of COPD or pulmonary fibrosis during the preceding 3 months. This study was approved by the institutional research ethics committee of Shinshu University School of Medicine.

\section{Imaging criteria}

Emphysema and diffuse parenchymal lung disease with significant pulmonary fibrosis were evaluated using chest HRCT as previously described. ${ }^{11,12}$ Briefly, emphysema was scored visually in the bilateral upper, middle, and lower lung fields according to the methods of Goddard et al. ${ }^{8}$ The score for each of the six dimensions was calculated according to percentage of low-attenuation area (\%LAA) in each lung field, as follows: score $0, \%$ LAA $<5 \%$; score $1,5 \% \leq \%$ LAA $<25 \%$; score $2,25 \% \leq \%$ LAA $<50 \%$; score $3,50 \% \leq \%$ LAA $<75 \%$; and score $4, \% \mathrm{LAA} \geq 75 \%$. The severity of emphysema was graded in accordance with the sum of the scores of the six dimensions, as follows: grade 0 , total score 0 ; grade 1 , total score 1-6; grade 2, total score 7-12; grade 3, total score 13-18; and grade 4, total score 19-24. The detection of diffuse parenchymal lung disease with significant pulmonary fibrosis on HRCT, defined as the presence of thick-walled bulla, honeycombing, reticular opacity, ground-glass opacity, consolidation, traction bronchiectasis, peribronchovascular interstitial thickening, and architectural distortion, was performed as previously described. ${ }^{3,13}$ The degree of pulmonary fibrosis was scored visually to grade the severity as previously described. ${ }^{14}$

Computed tomography (CT) images were analyzed independently by two pulmonologists (YK and KF) with no knowledge of the patients' clinical information. CPFE patients were characterized by the coexistence of significant emphysema (grade 2 or more, $\%$ LAA $\geq 25 \%$ ) and diffuse parenchymal lung disease with significant pulmonary fibrosis. COPD patients were characterized by the presence of 
significant emphysema (grade 2 or more, \%LAA $\geq 25 \%$ ) without significant pulmonary fibrosis.

\section{Pulmonary function tests}

Spirometry and diffusing capacity of the lung for carbon monoxide $\left(\mathrm{D}_{\mathrm{LCO}}\right)$ were measured using the Chestac- 8800 (Chest MI, Tokyo, Japan). Thoracic gas volume was measured using Body Box (MGC Diagnostics, Ann Arbor, MI, USA), after which the subject immediately inspired to total lung capacity (TLC) and expired maximally to residual volume (RV), allowing calculation of lung volumes and RV/TLC. Local Japanese reference data, ${ }^{15}$ developed by the Japanese Respiratory Society, were used to derive predicted values for $\mathrm{FEV}_{1}$ and vital capacity, while the predicted values for $\mathrm{D}_{\mathrm{LCO}}$ and lung volumes (thoracic gas volume, RV, and TLC) measured by body plethysmography were determined using the formulas described by Nishida et al ${ }^{16}$ and Boren et al, ${ }^{17}$ respectively.

Respiratory impedance was measured using IOS (MasterScreen ${ }^{\mathrm{TM}}$ IOS; CareFusion, Höchberg, Germany), as previously described..$^{18,19}$ Respiratory resistance (Rrs) and reactance (Xrs) at lower oscillation frequencies and Rrs at higher frequencies were evaluated at oscillation frequencies of $5 \mathrm{~Hz}$ (Rrs5 and Xrs5) and $20 \mathrm{~Hz}$ (Rrs20). We also measured the mean values of Xrs5 in separated inspiration and expiration of tidal breath, and evaluated the difference between the mean expiratory and inspiratory reactance $(\Delta \mathrm{Xrs} 5)$.

\section{Evaluation of dynamic hyperinflation following MPIH}

Dynamic hyperinflation was evaluated using MPIH by incrementally increasing the respiratory rate to 20,30 , and 40 breaths/minute as per our previous reports..$^{20,21}$ Inspiratory capacity (IC) was measured immediately after breathing at a resting respiratory rate for 30 seconds. The respiratory rate was increased to 20,30 , and 40 breaths/minute in 30 -second increments, and IC was again measured immediately after MPIH for 30 seconds at each respiratory rate. IC at the resting respiratory rate was expressed as $\mathrm{IC}_{\text {at rest }}$ IC at rates of 20,30 , and 40 breaths per minute was expressed as $\mathrm{IC}_{20}$, $\mathrm{IC}_{30}$, and $\mathrm{IC}_{40}$, respectively. Dynamic hyperinflation was evaluated according to the decrease in IC from $\mathrm{IC}_{\text {atrest }}$ to $\mathrm{IC}_{20}$, the decrease in $\mathrm{IC}$ from $\mathrm{IC}_{\text {at rest }}$ to $\mathrm{IC}_{30}$, and the decrease in IC from $\mathrm{IC}_{\text {at rest }}$ to $\mathrm{IC}_{40}$.

\section{Data analysis}

The values shown in the text, figures, and tables represent the means \pm standard error of the mean. The data distribution of the variables in the various groups was first assessed using Bartlett's test. When the data for the variables showed a normal distribution, they were compared using one-way analysis of variance, followed by multiple comparisons according to the Tukey-Kramer method. When the data for the variables did not show a normal distribution, the variables were compared using the Kruskal-Wallis test, followed by multiple comparisons among groups with the nonparametric TukeyKramer method. Simple correlations between variables were examined by calculating Pearson's product correlation coefficient. Categorical variables of the severity of pulmonary fibrosis on chest HRCT were evaluated using Fisher's exact test. All statistical analyses were performed using Windowscompatible software (StatFlex version 5.0; Artech Co., Ltd., Osaka, Japan). $P$-values less than 0.05 were considered to be significant in all statistical analyses.

\section{Results}

Clinical characteristics and pulmonary function parameters of the $\mathrm{CPFE} \mathrm{OB}^{-}, \mathrm{CPFE} \mathrm{OB}^{+}$, and $\mathrm{COPD}$ groups are shown in Table 1. In imaging findings, LAA scores on chest HRCT were significantly lower in the $\mathrm{CPFE} \mathrm{OB}^{-}$group than in the

Table I Characteristics of the combined pulmonary fibrosis and emphysema (CPFE) without airflow obstruction $\left(\mathrm{OB}^{-}\right)$, with airflow obstruction $\left(\mathrm{CPFE} \mathrm{OB}^{+}\right)$, and chronic obstructive pulmonary disease (COPD) groups

\begin{tabular}{|c|c|c|c|}
\hline & $\begin{array}{l}\text { CPFE OB- } \\
(n=20)\end{array}$ & $\begin{array}{l}\begin{array}{l}\text { CPFE OB }^{+} \\
(n=I I)\end{array}\end{array}$ & $\begin{array}{l}\text { COPD } \\
(n=49)\end{array}$ \\
\hline Age, years & $67.8 \pm 2.2$ & $73.6 \pm 1.9$ & $70.9 \pm 1.1$ \\
\hline Sex, male/female & $20 / 0$ & $\mathrm{II} / 0$ & $44 / 5$ \\
\hline $\mathrm{BMI}, \mathrm{kg} / \mathrm{m}^{2}$ & $23.8 \pm 0.5^{*}$ & $22.6 \pm 0.9$ & $21.9 \pm 0.5$ \\
\hline LAA score on chest HRCT & $11.0 \pm 1.2^{* *,+\dagger}$ & $19.5 \pm 1.4$ & $16.2 \pm 1.0$ \\
\hline \multicolumn{4}{|c|}{ Severity of pulmonary fibrosis on chest HRCT } \\
\hline Minimum & $7(35 \%)^{\dagger}$ & $8(72.7 \%)$ & NA \\
\hline Moderate & $8(40 \%)$ & $2(18.2 \%)$ & NA \\
\hline Severe & $5(25 \%)$ & I (9.1\%) & NA \\
\hline \multicolumn{4}{|l|}{ Pulmonary function } \\
\hline VC, \% of predicted & $91.6 \pm 5.2^{\dagger}$ & $108.8 \pm 3.4$ & $97.0 \pm 2.6$ \\
\hline $\mathrm{FEV}_{l}, \mathrm{~L}$ & $2.43 \pm 0.12^{* *, t \dagger}$ & $1.79 \pm 0.13$ & $1.53 \pm 0.09$ \\
\hline $\mathrm{FEV}_{1}, \%$ of predicted & $87.1 \pm 4.9 * *, \dagger \dagger$ & $64.9 \pm 4.4$ & $64.3 \pm 3.0$ \\
\hline $\mathrm{FEV}_{\mathrm{I}} / \mathrm{FVC}, \%$ & $79.5 \pm 1.5 * *,+\dagger$ & $52.7 \pm 3.5$ & $52.5 \pm 1.7$ \\
\hline $\mathrm{RV}, \%$ of predicted & $82.9 \pm 7.2^{* *,+\dagger}$ & $143.9 \pm 16.9 * *$ & $198.0 \pm 9.6$ \\
\hline TLC, \% of predicted & $83.0 \pm 5.0 * *,+\dagger$ & $116.8 \pm 6.6$ & $125.3 \pm 3.3$ \\
\hline RV/TLC, \% & $32.0 \pm 2.2^{* *, \dagger}$ & $40.6 \pm 2.4 * *$ & $51.6 \pm 1.4$ \\
\hline $\mathrm{D}_{\mathrm{LCO}}, \%$ of predicted & $39.0 \pm 3.8 * *$ & $38.6 \pm 6.2 * *$ & $60.0 \pm 2.7$ \\
\hline $\mathrm{D}_{\mathrm{LCO}} / \mathrm{VA}, \%$ of predicted & $71.9 \pm 7.1^{+t}$ & $42.3 \pm 5.4^{* *}$ & $71.9 \pm 3.4$ \\
\hline
\end{tabular}

Notes: $* P<0.05$ and $* * P<0.01$ versus COPD; ${ }^{t} P<0.05$ and ${ }^{t+P}<0.01$ versus CPFE $\mathrm{OB}^{+}$. Values are means \pm standard error of the mean.

Abbreviations: BMI, body mass index; LAA, low attenuation area; HRCT, highresolution computed tomography; $\mathrm{FEV}_{1}$, forced expiratory volume in I second; FVC, forced vital capacity; RV, residual volume; TLC, total lung capacity; $\mathrm{D}_{\text {LCo, }}$, diffusing capacity of lung for carbon monoxide; $D_{\mathrm{LCO}} / \mathrm{NA}, \mathrm{D}_{\mathrm{LcO}}$ corrected for alveolar volume; NA, not applicable; VC, vital capacity. 
$\mathrm{CPFE} \mathrm{OB}^{+}$and COPD groups. Significantly more patients showed minimum pulmonary fibrosis in the $\mathrm{CPFE} \mathrm{OB}^{+}$ group than in the $\mathrm{CPFE} \mathrm{OB}^{-}$group, which suggests that the severity of pulmonary fibrosis was greater in the $\mathrm{CPFE} \mathrm{OB}^{-}$ group. In pulmonary function, percentage-predicted $\mathrm{D}_{\mathrm{LCO}}$ was significantly lower in the $\mathrm{CPFE} \mathrm{OB}^{-}$and $\mathrm{CPFE} \mathrm{OB}^{+}$ groups than in the COPD group. DLco corrected for alveolar volume (VA), $\left(\mathrm{D}_{\mathrm{LCO}} / \mathrm{VA}\right)$. Percentage-predicted $\mathrm{D}_{\mathrm{LCO}} / \mathrm{VA}$ was significantly lower in the $\mathrm{CPFE} \mathrm{OB}^{+}$group than in the CPFE $\mathrm{OB}^{-}$and $\mathrm{COPD}$ groups. There was a significant correlation between LAA scores and $\mathrm{D}_{\mathrm{LCO}} / \mathrm{VA}$ among all CPFE patients ( $r=-0.76, P=0.0003)$.

Rrs5, Rrs20, and Rrs5-Rrs20 were significantly lower in the $\mathrm{CPFE} \mathrm{OB}^{-}$group than in the COPD group (Figure 1). These parameters tended to be higher in the CPFE $\mathrm{OB}^{+}$ group than in the $\mathrm{CPFE} \mathrm{OB}^{-}$group, although there were no significant differences. Xrs5 was significantly less negative in the CPFE $\mathrm{OB}^{-}$group than in the COPD group. $\triangle \mathrm{Xrs5}$, indicating the difference in mean Xrs5 during the inspiration and expiration phases and representing easy collapsibility of small airways during expiration of the tidal breath, was significantly greater in the COPD group than in the CPFE $\mathrm{OB}^{+}$group.

\section{Dynamic hyperinflation following MPIH}

$\mathrm{IC}$ at rest was significantly lower in the $\mathrm{CPFE} \mathrm{OB}^{-}$group than in the $\mathrm{CPFE} \mathrm{OB}^{+}$and $\mathrm{COPD}$ groups (Figure 2). Although there were no significant differences in $\mathrm{IC}_{20}, \mathrm{IC}_{30}$, and $\mathrm{IC}_{40}$ among the three groups, these parameters tended to be lower in the $\mathrm{CPFE} \mathrm{OB}^{-}$group. IC incrementally decreased as the respiratory rate was incrementally increased in the COPD group only. $\mathrm{IC}_{\text {rest-20, }}, \mathrm{IC}_{\text {rest-30 }}$ and $\mathrm{IC}_{\text {rest-40 }}$, representing dynamic hyperinflation, had significantly more negative values in

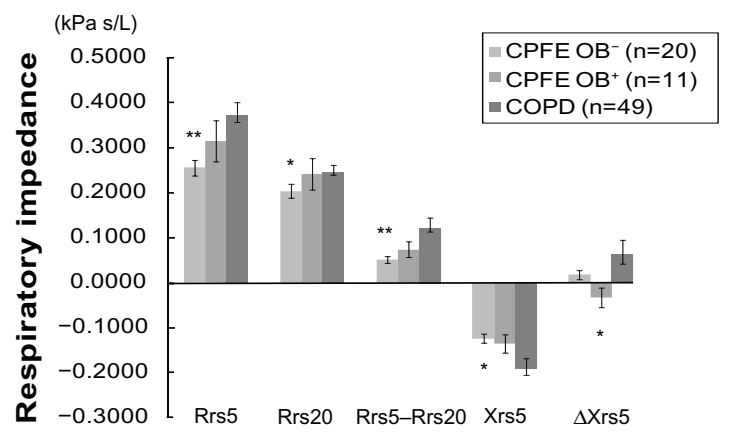

Figure I Respiratory impedance in the CPFE $\mathrm{OB}^{-}, \mathrm{CPFE} \mathrm{OB}^{+}$, and COPD groups. Notes: $* P<0.05, * * P<0.01$ versus $C O P D$. Values are means \pm standard error of the mean.

Abbreviations: CPFE, combined pulmonary fibrosis and emphysema; OB-, without airflow obstruction; $\mathrm{OB}^{+}$, with airflow obstruction; $\mathrm{COPD}$, chronic obstructive pulmonary disease; Rrs5, respiratory resistance at $5 \mathrm{~Hz}$; Rrs20, respiratory resistance at $20 \mathrm{~Hz}$; Xrs5, respiratory reactance at $5 \mathrm{~Hz} ; \triangle \mathrm{Xrs5}$, within-breath changes in Xrs5.

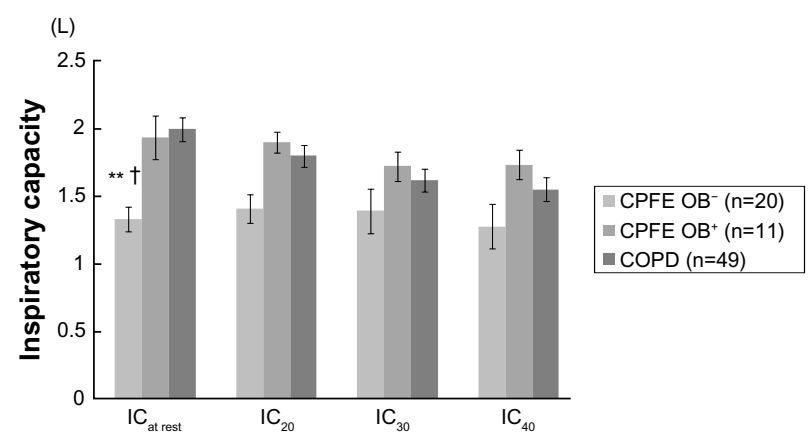

Figure $\mathbf{2}$ Inspiratory capacity as the respiratory rate was incrementally increased in the CPFE OB' ${ }^{-}, \mathrm{CPFE} \mathrm{OB}^{+}$, and COPD groups.

Notes: Dynamic hyperinflation following metronome-paced incremental hyperventilation in the combined pulmonary fibrosis and emphysema (CPFE) without airflow obstruction $\left(\mathrm{OB}^{-}\right)$, with airflow obstruction (CPFE $\left.\mathrm{OB}^{+}\right)$, and chronic obstructive pulmonary disease (COPD) groups. Inspiratory capacity (IC) from resting respiratory rate to rates of 20,30 , and 40 breaths per minute. $* * P<0.0$ I versus COPD; ${ }^{+} P<0.05$ versus $C P F E ~ O B^{+}$. Values are means \pm standard error of the mean.

the COPD group than in the $\mathrm{CPFE} \mathrm{OB}^{-}$group (Figure 3). These variables tended to be more negative in the $\mathrm{CPFE} \mathrm{OB}^{+}$ group than in the $\mathrm{CPFE} \mathrm{OB}^{-}$group, although there were no significant differences.

\section{Discussion}

This is the first report to evaluate pulmonary function impairment in CPFE patients divided into two groups according to the presence or absence of airflow obstruction based on spirometry. LAA scores, representing the degree of emphysema on chest HRCT, were significantly higher in the $\mathrm{CPFE} \mathrm{OB}^{+}$group than in the $\mathrm{CPFE} \mathrm{OB}^{-}$group. In contrast, more patients showed minimum pulmonary fibrosis in the $\mathrm{CPFE} \mathrm{OB}^{+}$group than in the $\mathrm{CPFE} \mathrm{OB}^{-}$group. Impairment of diffusion capacity was severe in both the CPFE $\mathrm{OB}^{-}$

(L)

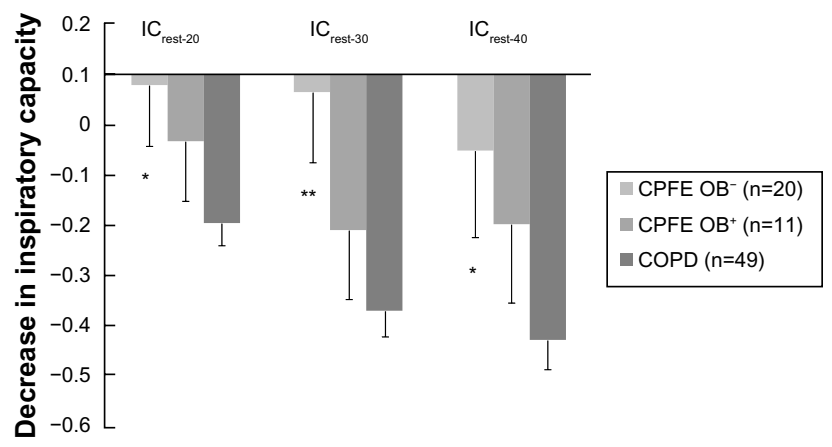

Figure 3 Decrease in inspiratory capacity from resting respiratory rates to the rate of 20,30 , and 40 breaths per minute, representing dynamic hyperinflation, in the $\mathrm{CPFE} \mathrm{OB} \mathrm{O}^{-}, \mathrm{CPFE} \mathrm{OB}^{+}$, and $\mathrm{COPD}$ groups.

Notes: Dynamic hyperinflation following metronome-paced incremental hyperventilation in the combined pulmonary fibrosis and emphysema (CPFE) without airflow obstruction $\left(\mathrm{OB}^{-}\right)$, with airflow obstruction (CPFE $\left.\mathrm{OB}^{+}\right)$, and chronic obstructive pulmonary disease (COPD) groups. Decrease in inspiratory capacity (IC) from resting respiratory rate to rates of 20,30, and 40 breaths per minute. $* P<0.05$, $* * P<0.01$ versus COPD. Values are means \pm standard error of the mean. 
and $\mathrm{CPFE} \mathrm{OB}^{+}$groups. Neither lung hyperinflation nor respiratory resistance were apparent in the $\mathrm{CPFE} \mathrm{OB}^{-}$group. Easy collapsibility of small airways during expiration of the tidal breath, expressed as $\Delta \mathrm{Xrs} 5$, was not apparent in the $\mathrm{CPFE} \mathrm{OB}^{+}$group compared with the COPD group. Dynamic hyperinflation following MPIH expressed as $\mathrm{IC}_{\text {rest-20 }}, \mathrm{IC}_{\text {rest-30, }}$, and $\mathrm{IC}_{\text {rest-40 }}$ was significantly greater in the COPD group than in the $\mathrm{CPFE} \mathrm{OB}^{-}$group and also tended to be greater in the $\mathrm{CPFE} \mathrm{OB}^{+}$group than in the CPFE $\mathrm{OB}^{-}$group.

We found that the proportions of emphysema and pulmonary fibrosis on chest HRCT were different between the $\mathrm{CPFE} \mathrm{OB}^{+}$and $\mathrm{CPFE} \mathrm{OB}^{-}$groups in the present study. There is a possibility that CPFE is associated with clinical phenotypes that can be classified according to the findings on chest HRCT. That is to say, CPFE may be classified into the "emphysema-dominant" phenotype or the "fibrosisdominant" phenotype, which may involve different mechanisms underlying pulmonary function impairment, such as irreversible airflow obstruction and dynamic hyperinflation. These findings may thus allow us to significantly improve our understanding of radiological and physiological heterogeneity of CPFE.

Our previous study revealed that the annual decrease in $\mathrm{D}_{\mathrm{LCO}}$ and $\mathrm{D}_{\mathrm{LCO}} / \mathrm{VA}$ was greater in CPFE patients than in COPD patients. ${ }^{13}$ Longitudinal changes in $\mathrm{D}_{\mathrm{LCO}}$ have been shown to have prognostic value in patients with idiopathic pulmonary fibrosis. ${ }^{22-25}$ These findings suggest that it is helpful to measure longitudinal changes in $\mathrm{D}_{\mathrm{LCO}} / \mathrm{VA}$ as a prognostic predictor in CPFE patients. Indeed, severe $\mathrm{D}_{\mathrm{LCO}} / \mathrm{VA}$ reduction is frequently related to pulmonary hypertension, ${ }^{26}$ which is often observed in CPFE patients. ${ }^{1,27}$ The presence of pulmonary hypertension is a critical determinant of the prognosis of CPFE. ${ }^{1,28}$ In the present study, $\mathrm{D}_{\mathrm{LCO}} / \mathrm{VA}$ was significantly lower in the $\mathrm{CPFE} \mathrm{OB}^{+}$group. We also found a significant correlation between $\mathrm{D}_{\mathrm{LCO}} / \mathrm{VA}$ and the degree of emphysema on chest HRCT among all CPFE patients. These findings suggest that $\mathrm{CPFE} \mathrm{OB}^{+}$patients with more emphysema have worse survival than $\mathrm{CPFE} \mathrm{OB}^{-}$patients. Further studies are needed to investigate the association between survival and airflow obstruction in CPFE patients.

The parameters of respiratory impedance measured using IOS were relatively normal in the CPFE $\mathrm{OB}^{-}$group, despite the presence of emphysema, compared with those observed in the healthy control group in our previous study. ${ }^{19}$ Interestingly, in the present study, $\Delta \mathrm{Xrs} 5$ was significantly lower in the CPFE $\mathrm{OB}^{+}$group than in the COPD group, despite the presence of more emphysema, whereas Rrs5, Rrs20, and Rrs5-Rrs20 tended to be higher in the CPFE
$\mathrm{OB}^{+}$group than in the $\mathrm{CPFE} \mathrm{OB}^{-}$group. When airflow obstruction is present, the oscillatory signal cannot pass through the choke points to reach the alveoli, ${ }^{29}$ resulting in a marked reduction in apparent compliance; therefore, the value of Xrs5 changes to be more negative physiologically in COPD patients. ${ }^{30} \Delta \mathrm{Xrs} 5$ has been suggested to reflect the number and distribution of choke points within the bronchial tree, representing the overall distribution of expiratory flow limitation during tidal breathing in COPD patients. ${ }^{31-33}$ These findings suggest that increased traction caused by pulmonary fibrosis prevents airway collapsibility during expiration of the tidal breath as a result of loss of alveolar attachment and elastic recoil at the site of small airways in CPFE patients. $\Delta$ Xrs5 may be a useful indicator for making a diagnosis of CPFE and evaluating the extent of fibrotic component in CPFE physiologically.

The parameters of dynamic hyperinflation following MPIH were relatively normal in the $\mathrm{CPFE} \mathrm{OB}^{-}$group, despite the presence of emphysema, compared with those observed in the healthy control group in our previous study, ${ }^{20}$ suggesting that dynamic hyperinflation is not associated with pulmonary function impairment in CPFE OB patients without airflow obstruction. However, there is a possibility that dynamic hyperinflation is associated with pulmonary function impairment in some $\mathrm{CPFE} \mathrm{OB}^{+}$patients as well as in COPD patients. Further studies involving a larger number of patients are needed to confirm the present results. On the other hand, a previous study revealed that pulmonary hypertension is often observed in CPFE patients, ${ }^{1,27-28}$ and is associated with dyspnea during exercise and/or decreased exercise tolerance in CPFE patients. ${ }^{28}$ Pulmonary hypertension may thus influence pulmonary function impairment in CPFE patients. Indeed, severe $\mathrm{D}_{\mathrm{LCO}} / \mathrm{VA}$ reduction is frequently related to pulmonary hypertension. ${ }^{26}$

There were several limitations in this study. First, this was a single-center, uncontrolled-design retrospective study with a lack of statistical power, as the sample size was small in the CPFE $\mathrm{OB}^{+}$group ( $\left.\mathrm{n}=11\right)$. This study was performed to reveal that CPFE is a heterogeneous disease and has distinct phenotypes physiologically, in spite of the small sample size. Additional prospective studies with large sample sizes are required to confirm our results. Second, the assessment of emphysema on chest HRCT was performed according to a visual scoring method, rather than software-based quantification of the degree of emphysema. However, the reproducibility of visual scoring was demonstrated in our previous report. ${ }^{12}$ In addition, we did not measure the exact areas of fibrosis on chest HRCT. CPFE was diagnosed according to 
our criteria as previously described. ${ }^{3,13}$ Third, the differences in pharmacotherapy between the CPFE and COPD groups might have influenced the results.

In conclusion, the mechanisms underlying impairment of physiological function may differ among $\mathrm{CPFE} \mathrm{OB}^{+}$ patients, $\mathrm{CPFE} \mathrm{OB}^{-}$patients, and COPD patients. CPFE is a heterogeneous disease, and may have distinct phenotypes physiologically and radiologically.

\section{Disclosure}

The authors report no conflicts of interest in this work.

\section{References}

1. Cottin V, Nunes H, Brillet PY, et al. Combined pulmonary fibrosis and emphysema: a distinct underrecognised entity. Eur Respir J. 2005;26:586-593.

2. Jankowich MD, Polsky M, Klein M, Rounds S. Heterogeneity in combined pulmonary fibrosis and emphysema. Respiration. 2008;75:411-417.

3. Kitaguchi Y, Fujimoto K, Hanaoka M, Kawakami S, Honda T, Kubo K. Clinical characteristics of combined pulmonary fibrosis and emphysema. Respirology. 2010;15:265-271.

4. Grubstein A, Bendayan D, Schactman I, Cohen M, Shitrit D, Kramer MR. Concomitant upper-lobe bullous emphysema, lower-lobe interstitial fibrosis and pulmonary hypertension in heavy smokers: report of eight cases and review of the literature. Respir Med. 2005;99:948-954.

5. Mura M, Zompatori M, Pacilli AM, Fasano L, Schiavina M, Fabbri M. The presence of emphysema further impairs physiologic function in patients with idiopathic pulmonary fibrosis. Respir Care. 2006;51: 257-265.

6. Jankowich MD, Rounds SI. Combined pulmonary fibrosis and emphysema syndrome: a review. Chest. 2012;141:222-231.

7. Cottin V. The impact of emphysema in pulmonary fibrosis. Eur Respir Rev. 2013;22:153-157.

8. Goddard PR, Nicholson EM, Laszlo G, Watt I. Computed tomography in pulmonary emphysema. Clin Radiol. 1982;33:379-387.

9. Gotway MB, Freemer MM, King TE Jr. Challenges in pulmonary fibrosis. 1: Use of high resolution CT scanning of the lung for the evaluation of patients with idiopathic interstitial pneumonias. Thorax. 2007;62:546-553.

10. Global initiative for chronic Obstructive Lung Disease. Global Strategy for the Diagnosis, Management, and Prevention of Chronic Obstructive Pulmonary Disease. Bethesda (MD): GOLD; 2013.

11. Kitaguchi Y, Fujimoto K, Kubo K, Honda T. Characteristics of COPD phenotypes classified according to the findings of HRCT. Respir Med. 2006;100:1742-1752.

12. Fujimoto K, Kitaguchi Y, Kubo K, Honda T. Clinical analysis of chronic obstructive pulmonary disease phenotypes classified using highresolution computed tomography. Respirology. 2006;11:731-740.

13. Kitaguchi Y, Fujimoto K, Hayashi R, Hanaoka M, Honda T, Kubo K. Annual changes in pulmonary function in combined pulmonary fibrosis and emphysema: over a 5-year follow-up. Respir Med. 2013;107: 1986-1992.

14. Kurashima K, Takayanagi N, Tsuchiya N, et al. The effect of emphysema on lung function and survival in patients with idiopathic pulmonary fibrosis. Respirology. 2010;15:843-848.
15. Japanese Society of Chest Disease. Standards of pulmonary function tests for Japanese. Jpn J Respir Dis. 1993;31:421-427.

16. Nishida S, Kambe M, Sewake N, Takano M, Kawane H. [Pulmonary function in healthy subjects and its prediction. 5. Pulmonary diffusing capacity in adults]. Rinsho Byori. 1976;24:941-947. Japanese.

17. Boren HG, Kory RC, Syner JC, Callahan R. The Veterans Administration-Army cooperative study of pulmonary function. 2. The lung volume and its subdivisions in normal men. Am J Med. 1966;41:96-101.

18. Van de Woestijne KP, Desager KN, Duiverman EJ, Marchal F. Recommendations for measurement of respiratory input impedance by means of the forced oscillation method. Eur Respir Rev. 1994;19: 235-237.

19. Kanda S, Fujimoto K, Komatsu Y, Yasuo M, Hanaoka M, Kubo K. Evaluation of respiratory impedance in asthma and COPD by an impulse oscillation system. Intern Med. 2010;49:23-30.

20. Fujimoto K, Yoshiike F, Yasuo M, et al. Effects of bronchodilators on dynamic hyperinflation following hyperventilation in patients with COPD. Respirology. 2007;12:93-99.

21. Fujimoto K, Kitaguchi Y, Kanda S, Urushihata K, Hanaoka M, Kubo K. Comparison of efficacy of long-acting bronchodilators in emphysema dominant and emphysema nondominant chronic obstructive pulmonary disease. Int J Chron Obstruct Pulmon Dis. 2011;6:219-227.

22. Schwartz DA, Helmers RA, Galvin JR, et al. Determinants of survival in idiopathic pulmonary fibrosis. Am J Respir Crit Care Med. 1994;149: 450-454.

23. Flaherty KR, Mumford JA, Murray S, et al. Prognostic implications of physiologic and radiographic changes in idiopathic interstitial pneumonia. Am J Respir Crit Care Med. 2003;168:543-548.

24. Collard HR, King TE Jr, Bartelson BB, Vourlekis JS, Schwarz MI, Brown KK. Changes in clinical and physiologic variables predict survival in idiopathic pulmonary fibrosis. Am J Respir Crit Care Med. 2003; 168:538-542.

25. Flaherty KR, Andrei AC, Murray S, et al. Idiopathic pulmonary fibrosis: prognostic value of changes in physiology and six-minute-walk test. Am J Respir Crit Care Med. 2006;174:803-809.

26. Kiakouama L, Cottin V, Glerant JC, Bayle JY, Mornex JF, Cordier JF. Conditions associated with severe carbon monoxide diffusion coefficient reduction. Respir Med. 2011;105:1248-1256.

27. Mejía M, Carrillo G, Rojas-Serrano J, et al. Idiopathic pulmonary fibrosis and emphysema: decreased survival associated with severe pulmonary arterial hypertension. Chest. 2009;136:10-15.

28. Cottin V, Le Pavec J, Prévot G, et al. Pulmonary hypertension in patients with combined pulmonary fibrosis and emphysema syndrome. Eur Respir J. 2010;35:105-111.

29. Dawson SV, Elliott EA. Wave-speed limitation on expiratory flow a unifying concept. J Appl Physiol Respir Environ Exerc Physiol. 1977;43:498-515.

30. O'Donnell DE, Voduc N, Fitzpatrick M, Webb KA. Effect of salmeterol on the ventilatory response to exercise in chronic obstructive pulmonary disease. Eur Respir J. 2004;24:86-94.

31. Dellacà RL, Santus P, Aliverti A, et al. Detection of expiratory flow limitation in COPD using the forced oscillation technique. Eur Respir J. 2004;23:232-240.

32. Dellacà RL1, Rotger M, Aliverti A, Navajas D, Pedotti A, Farré R. Noninvasive detection of expiratory flow limitation in COPD patients during nasal CPAP. Eur Respir J. 2006;27:983-991.

33. Dellacà RL, Duffy N, Pompilio PP, et al. Expiratory flow limitation detected by forced oscillation and negative expiratory pressure. Eur Respir J. 2007;29:363-374. 
International Journal of COPD

\section{Publish your work in this journal}

The International Journal of COPD is an international, peer-reviewed journal of therapeutics and pharmacology focusing on concise rapid reporting of clinical studies and reviews in COPD. Special focus is given to the pathophysiological processes underlying the disease, intervention programs, patient focused education, and self management protocols.

This journal is indexed on PubMed Central, MedLine and CAS. The manuscript management system is completely online and includes a very quick and fair peer-review system, which is all easy to use. Visit $\mathrm{http}: / /$ www.dovepress.com/testimonials.php to read real quotes from published authors.

Submit your manuscript here: http://www.dovepress.com/international-journal-of-copd-journal 